\title{
Effect of current density on magnetic properties of electrodeposited Fe-Ni films prepared in a citric-acid-based-bath
}

\author{
T. Yanai, ${ }^{1}$ T. Shimokawa, ${ }^{1, a)}$ Y. Watanabe,${ }^{1}$ T. Ohgai, ${ }^{1}$ M. Nakano, ${ }^{1}$ K. Suzuki, ${ }^{2}$ \\ and $\mathrm{H}$. Fukunaga ${ }^{1}$ \\ ${ }^{1}$ Graduate school of Engineering, Nagasaki University, Nagasaki, Nagasaki 852-8521, Japan \\ ${ }^{2}$ Department of Material Engineering, Monash University, Clayton VIC 3800, Australia
}

(Presented 5 November 2013; received 23 September 2013; accepted 7 November 2013; published online 19 February 2014)

\begin{abstract}
In order to improve soft magnetic properties of electrodeposited Fe-Ni films prepared in a citricacid-based bath, we investigated the effect of the current density on the grain size and the coercivity of $\mathrm{Fe}_{22} \mathrm{Ni}_{78}$ and $\mathrm{Fe}_{35} \mathrm{Ni}_{65}$ films. Consequently, we confirmed that increase in a current density reduces the coercivity and the grain size. This result suggests the exchange softening effect works effectively by the reduction in the grain size. We confirmed that the increase in the current density is effective to improve in soft magnetic properties of Fe-Ni films electrodeposited in the citric-acid-based bath. (C 2014 AIP Publishing LLC. [http://dx.doi.org/10.1063/1.4865321]
\end{abstract}

\section{INTRODUCTION}

Fe-Ni alloys have good soft magnetic properties such as low coercivity and high permeability, and their films are widely used in electric devices for shielding and converging of magnetic flux. The commonly used plating bath for the Fe-Ni films contains a boric acid for the purpose of $\mathrm{pH}$ buffering in the bath. Although the boric acid plays an important role in the plating process of $\mathrm{Ni}$ and $\mathrm{Fe}-\mathrm{Ni}$ films, ${ }^{1,2}$ waste baths containing boron are restricted by the regulation of environmental protection in Japan. Therefore, a plating bath without the boric acid is preferable for mass-product $\mathrm{Fe}-\mathrm{Ni}$ films. Recently, we applied a plating bath that boric acid was replaced by organic acids such as citric and tartaric ones for preparation of the electrodeposited Fe-Ni films, and we confirmed that the films prepared in organic-acid-based baths have good soft magnetic properties. ${ }^{3-5}$ In this study, we focused on a current density during the electrodeposition. It is well-known that the current density affects various properties of electrodeposited films and a high current density tends to reduce grain sizes of the films. ${ }^{6-10}$ It is also well-known that reduction in a grain size improves soft magnetic properties for nanocrystalline soft magnetic materials due to the exchange softening effect. ${ }^{11-17}$ Therefore, we investigated the effect of the current density on the grain sizes and the coercivity of the electrodeposited Fe-Ni films in order to improve soft magnetic properties of our previously reported ones.

\section{EXPERIMENTAL PROCEDURES}

\section{A. Preparation of electrodeposited Fe-Ni films}

The electrolyte of the plating bath contained the following: $275 \mathrm{~g} / \mathrm{l}$ of $\mathrm{NiSO}_{4} \cdot 6 \mathrm{H}_{2} \mathrm{O}$ (nickel sulfate), $50 \mathrm{~g} / \mathrm{l}$ of $\mathrm{NaCl}$ (sodium chloride), $5 \mathrm{~g} / \mathrm{l}$ of $\mathrm{C}_{7} \mathrm{H}_{4} \mathrm{NNaO}_{3} \mathrm{~S} \cdot 2 \mathrm{H}_{2} \mathrm{O}$ (saccharine sodium), and $30 \mathrm{~g} / \mathrm{l}$ of $\mathrm{C}_{6} \mathrm{H}_{8} \mathrm{O}_{7} \cdot \mathrm{H}_{2} \mathrm{O}$ (citric acid). In order to control the composition of the Fe-Ni films, we changed the

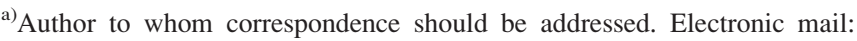
bb52112215@cc.nagasaki-u.ac.jp
}

amount of $\mathrm{FeSO}_{4} \cdot 7 \mathrm{H}_{2} \mathrm{O}$ (iron sulfate) from 20 to $65 \mathrm{~g} / \mathrm{l}$. In this experiment, $\mathrm{pH}$ in the bath was not adjusted (approximately 1.2). An anode and cathode were $5 \mathrm{~mm}$-wide and $500 \mu$ m-thick $\mathrm{Ni}$ and $\mathrm{Cu}$ plates, respectively. The Fe-Ni films were electrodeposited on the $75 \mathrm{~mm}^{2}-\mathrm{Cu}$ plate. In order to investigate the effect of the current density on the grain size and the coercivity of the electrodeposited Fe-Ni films, we changed the dc current density from 67 to $330 \mathrm{~mA} / \mathrm{cm}^{2}$. The film thicknesses were adjusted at approximately $20 \mu \mathrm{m}$ by the changes in the deposition time from 4.5 to $28.5 \mathrm{~min}$. The bath temperature was kept at $50^{\circ} \mathrm{C}$ during the electrodeposition.

\section{B. Measurements}

The thicknesses and the dc-hysteresis loops of the electrodeposited $\mathrm{Fe}-\mathrm{Ni}$ films were measured with a micrometer (Mitutoyo CPM15-25 MJ) and a B-H tracer (Riken Denshi BHS-40) operated at a field sweep rate of $50 \mathrm{mHz}$, respectively. The maximum excitation field of approximately $4 \mathrm{kA} / \mathrm{m}$ was used for the B-H measurements and the coercivity was determined from the loop. The compositions and crystal structures of the films were analyzed by EDX (Hitachi High-technologies S-3000) and XRD (Rigaku Rint 2000), respectively. The thicknesses and the compositions of the films were determined by averaging the values obtained for approximately every $7 \mathrm{~mm}^{2}$ (12 points) and $9 \mathrm{~mm}^{2}$ (9 points), respectively. All measurements were carried out for the Fe-Ni films in an as-deposited state.

\section{RESULTS AND DISCUSSION}

Figure 1 shows Fe content and thickness of the films as a function of current density. The films shown in Fig. 1 were prepared in the citric-acid-based bath with iron sulfate content of $35 \mathrm{~g} / \mathrm{l}$. With increasing the current density from 67 to $330 \mathrm{~mA} / \mathrm{cm}^{2}$, the Fe content of the films was decreased from 42 to 22 at. $\%$ and the thickness was increased from 8 to $40 \mu \mathrm{m}$. In the $\mathrm{Fe}-\mathrm{Ni}$ alloys, their magnetic properties are strongly affected by their composition. As shown in Fig. 1, since the composition of the films depends on the current 


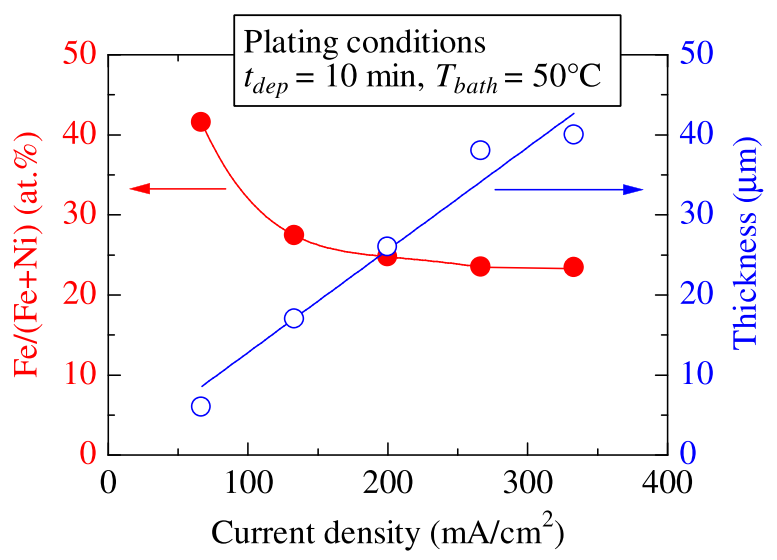

FIG. 1. Fe content and thickness of the Fe-Ni films as a function of current density. The films were prepared at various current densities and the same deposition time of $10 \mathrm{~min}$.

density, we could not discuss the effect of the current density on the magnetic properties of the film. Therefore, we changed the iron sulfate content in the plating bath to obtain the films with the same Fe composition in the following experiments. Furthermore, the thickness also affects the soft magnetic properties. In order to remove the effect of the thickness on the magnetic properties of the electrodeposited films, we controlled the thickness to relatively thick value of $20 \mu \mathrm{m}$ by the change in the deposition time

Figure 2 shows coercivity and current efficiency of the films with Fe content of approximately 22 at. \% (20.1-23.5 at. \%) as a function of current density. The thicknesses of all the films were controlled at approximately $20 \mu \mathrm{m}(19-21 \mu \mathrm{m})$. The current efficiency is calculated from the actual weight of the electrodeposited Fe-Ni film and the theoretical weight obtained by Faraday's law. As shown in Fig. 2, we obtained the tendencies of decrease in the coercivity and increase in the current efficiency with increasing the current density. The increasing tendency of the current efficiency almost agrees with the results for the bath containing the boric acid. ${ }^{18,19}$ From these results, we found that a high current density is

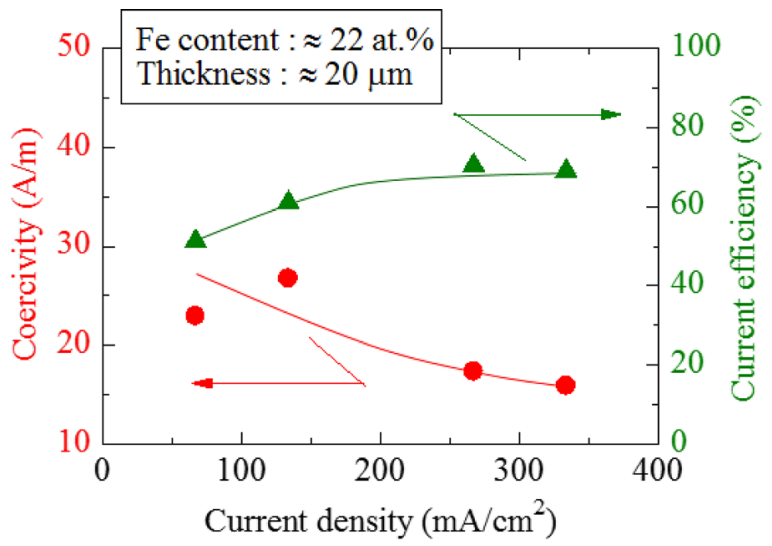

FIG. 2. Coercivity and current efficiency of the Fe-Ni films as a function of current density. The composition of the films was controlled at approximately $\mathrm{Fe}_{22} \mathrm{Ni}_{78}$ by the changes in the iron sulfate content in the plating bath. The thickness of the films was adjusted at approximately $20 \mu \mathrm{m}$ by the changes in the deposition time.

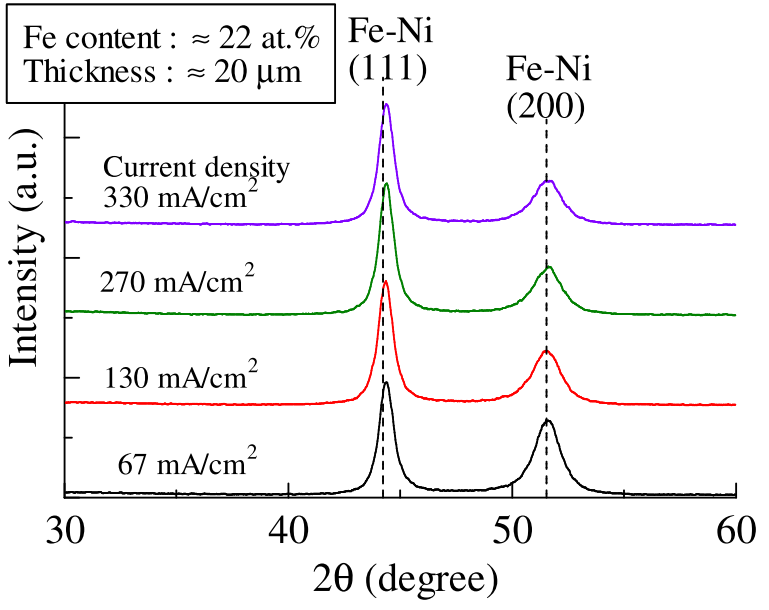

FIG. 3. Patterns of the Fe-Ni films prepared at various current densities. The current density was changed from 67 to $330 \mathrm{~mA} / \mathrm{cm}^{2}$.

effective to obtain the film with low coercivity and high current efficiency.

In order to clarify the origin of the reduction in the coercivity, we investigated the structure of the films. Figure 3 shows XRD patterns of the $\mathrm{Fe}_{22} \mathrm{Ni}_{78}$ films prepared at various current densities. The diffraction patters slightly became broad with increasing the current density. The broadening of diffraction pattern implies reduction in the grain size of $\mathrm{Fe}-\mathrm{Ni}$ crystalline phase. Figure 4 shows grain size of the films as a function of current density. The grain size was calculated by the Scherrer equation. For the calculation of the grain size, we used the full width at half maximum of (111) peak in Fig. 3 . In order to confirm the effect of the film composition on grain size, the result for the films with Fe content of approximately 35 at. \% (32.8-36.8 at. \%) is also shown in Fig.4. The inset in Fig. 4 indicates a hysteresis loop of the $\mathrm{Fe}_{22} \mathrm{Ni}_{78}$ film prepared at high current density of $330 \mathrm{~mA} / \mathrm{cm}^{2}$. As shown in Fig. 4, the grain sizes of both films were decreased with increasing the current density. We obtained the films with small grain size and low coercivity at the high current

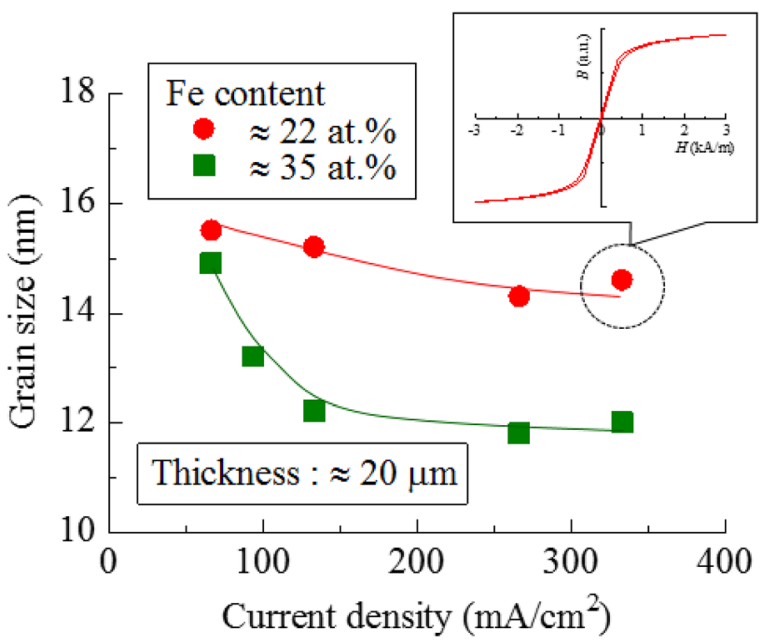

FIG. 4. Grain sizes of the $\mathrm{Fe}_{35} \mathrm{Ni}_{65}$ and $\mathrm{Fe}_{22} \mathrm{Ni}_{78}$ films as a function of current density. The thicknesses of the films were controlled at approximately $20 \mu \mathrm{m}$ by the change in the deposition time. The inset indicates the hysteresis loop of the $\mathrm{Fe}_{22} \mathrm{Ni}_{78}$ film prepared at high current density of $330 \mathrm{~mA} / \mathrm{cm}^{2}$. 


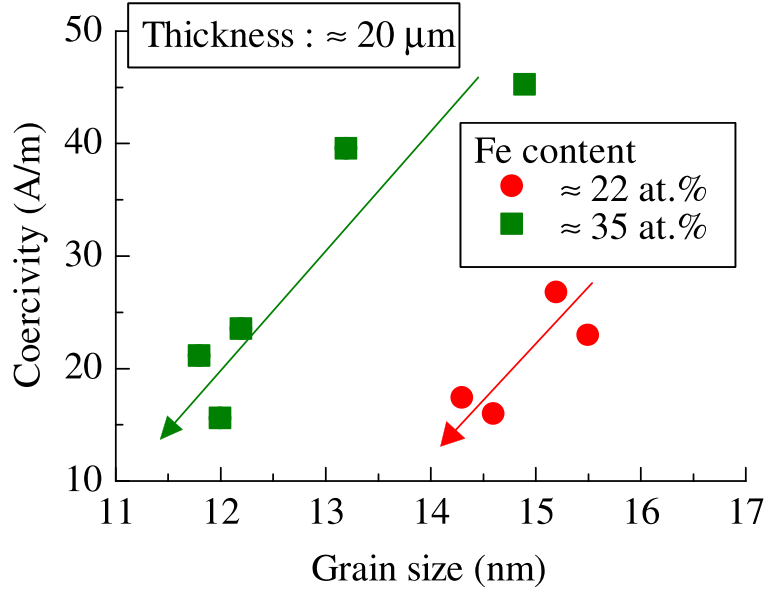

FIG. 5. Coercivities of the $\mathrm{Fe}_{35} \mathrm{Ni}_{65}$ and $\mathrm{Fe}_{22} \mathrm{Ni}_{78}$ films as a function of grain size.

densities. From the results in Fig. 2, the coercivity and the grain size were also decreased with increasing the current density. In order to clarify the effect of the grain size on the coercivity, we evaluated the relationship between the coercivity and the grain size. Figure 5 shows coercivity of the films as a function of grain size. The coercivity of the $\mathrm{Fe}_{22} \mathrm{Ni}_{78}$ films decreased with decreasing the grain sizes and that of the $\mathrm{Fe}_{35} \mathrm{Ni}_{65}$ films, and we found that the reduction in grain size is effective to reduce in the coercivity for the Fe-Ni films prepared in the citric-acid-based bath.

From the above-mentioned results, we found that an increase in the current density is one of hopeful method to improve in soft magnetic properties of Fe-Ni films electrodeposited in a citric-acid-based bath.

\section{CONCLUSIONS}

In this report, we have investigated the effect of the current density on the grain size and the magnetic properties of the electrodeposited Fe-Ni films prepared in the citric-acidbased bath. The obtained results are summarized as follows:
(1) The coercivities and the grain sizes of the $\mathrm{Fe}_{22} \mathrm{Ni}_{78}$ and $\mathrm{Fe}_{35} \mathrm{Ni}_{65}$ films were decreased with increasing the current density.

(2) A high current density promotes a crystal nucleation of $\mathrm{Fe}-\mathrm{Ni}$ phase and enables us to obtain the films with small grain size.

(3) A good correlation between the coercivity and the grain size was observed.

(4) Our results suggested that the improvement in soft magnetic property was attributed to the exchange softening effect between Fe-Ni grains.

${ }^{1}$ B. V. Tilak, A. S. Gendron, and M. A. Mosoiu, J. Appl. Electrochem. 7, 495 (1977).

${ }^{2}$ L. A. Toledo-Matos and M. A. Pech-Canul, J. Solid State Electrochem. 15, 1927 (2011).

${ }^{3}$ T. Shimokawa, T. Yanai, K. Takahashi, M. Nakano, K. Suzuki, and H. Fukunaga, IEEE Trans. Magn. 48, 2907 (2012).

${ }^{4}$ T. Shimokawa, T. Yanai, K. Takahashi, M. Nakano, K. Suzuki, and H. Fukunaga, J. Korean Phys. Soc. 62, 1963 (2013).

${ }^{5}$ T. Yanai, T. Shimokawa, Y. Watanabe, M. Nakano, and H. Fukunaga, IEEE Trans. Magn. 50(1), 1 (2014).

${ }^{6}$ A. M. Rashidi and A. Amadah, Surf. Coat. Technol. 202, 3772 (2008).

${ }^{7}$ N. Jiang, H. Meng, L. Song, and H. Yu, Int. J. Hydrogen Energy 35, 8056 (2010).

${ }^{8}$ S. M. Lari Baghal, M. Heydarzadeh Sohi, and A. Amadeh, Surf. Coat. Technol. 206, 4032 (2012).

${ }^{9}$ H. Gul, F. Kilic, S. Aslan, A. Alp, and H. Akbulut, Wear 267, 976 (2009).

${ }^{10}$ S. Cheng, J. Jang, B. A. Dempsey, and Br. E. Logan, Water Res. 45, 303 (2011).

${ }^{11}$ W. Bang, Y. Ko, H. Lee, K. Hong, J. Chung, and H. Lee, J. Electrochem. Soc. 155, D429 (2008).

${ }^{12}$ B. Koo and B. Yoo, Surf. Coat. Technol. 205, 740 (2010).

${ }^{13}$ Y. Yoshizawa, S. Oguma, and K. Yamauchi, J. Appl. Phys. 64, 6044 (1988).

${ }^{14}$ K. Suzuki, A. Makino, N. Kataoka, A. Inoue, and T. Masumoto, Mater. Trans. JIM 32, 93 (1991).

${ }^{15}$ M. A. Willard, M. Q. Huang, D. E. Laughlin, M. E. McHenry, J. O. Cross, V. G. Harris, and C. Franchetti, J. Appl. Phys. 85, 4421 (1999).

${ }^{16}$ G. Herzer, IEEE Trans. Magn. 26, 1397 (1990).

${ }^{17}$ H. Fukunaga and K. Inoue, Jpn. J. Appl. Phys., Part 1 31, 1347 (1992).

${ }^{18}$ J. M. Quemper, S. Nicolas, J. P. Grandchamp, A. Bosseboeuf, T. Bourouina, and E. D. Gergam, Sens. Actuators 74, 1 (1999).

${ }^{19}$ E. R. Spada, L. S. Oliveira, A. S. Rocha, A. A. Pasa, G. Zangari, and M. L. Sartorelli, J. Magn. Magn. Mater. 272-276, E891 (2004). 